\title{
The Relationship Among Somatotype Structures, Leg Volume, Leg Mass, Anaerobic Strength and Flexibility of Elite Male Athletes in Different Branches
}

\author{
İran Marangoz ${ }^{1}$, Dede Baştürk ${ }^{1}$ \\ ${ }^{1}$ Kırşehir Ahi Evran University, School of Physical Education and Sports, Kırşehir, Turkey \\ Correspondence: İrfan Marangoz, Kırşehir Ahi Evran University, School of Physical Education and Sports, Kırşehir, \\ Turkey.
}

Received: May 29, 2018

Accepted: June 20, $2018 \quad$ Online Published: June 25, 2018

doi:10.11114/jets.v6i7.3308

URL: https://doi.org/10.11114/jets.v6i7.3308

\begin{abstract}
This study aims to analyze the relationship among somatotype structures, leg volume, leg mass, anaerobic strength and flexibility of elite male athletes in different branches. 90 male athletes who study at School of Physical Education and Sport at University of Kırşehir Ahi Evran and are active in wrestling ( $\mathrm{n}=15)$, gymnastics (15), football (15), handball (15), volleyball (15) and basketball $(n=15)$ voluntarily participated in this study. Somatotype structures, leg volumes and leg masses of the participants were determined using Heath-Carter, Frustum and Hanavan methods, respectively. Vertical jump test was used to measure anaerobic performance, while sit-and-reach test was used for flexibility performance. Spearman correlation analysis was performed using SPSS 22.0 package program for Windows, and the level of significance was taken as 0.05 . As a result, a significant correlation was found between leg volume and mass and anaerobic performance values in football, volleyball, basketball, handball, wrestling and gymnastics, which indicates a decisive role in anaerobic performance. It was observed that athletes with a higher amount of leg volume and mass display a better anaerobic performance. The width of femur circumference and a high amount of muscle mass and fiber in the femur lead to a higher strength in muscles and maximizes the strength.
\end{abstract}

Keywords: leg volume, leg mass, somatotype, anaerobic strength, flexibility

\section{Introduction}

In addition to the physical structure, a combination of performance indicators such as speed, strength, endurance, agility, and flexibility positively influence an athlete's performance. Physical properties heavily affect the performance because physiological capacity depends on them. Physical suitability is of vital importance in a sport branch in order to reach a satisfactory performance (Marangoz, \& Polat, 2017). In many sports branches, the explosive form of a movement is considered as an important performance indicator. Similarly, an explosive anaerobic performance is a key factor of short-time and high intensity practices (Özkan, \& Kin İşler, 2010). Various studies underline the effect of age, gender, muscle type, muscle mass and cross section, hereditary traits, training and body composition on anaerobic performance (Bencke, Damsgaard, Saekmose, Jorgenson, Jorgenson, \& Klauen, 2002; Mayhew, Hancook, Rollisan, Ball, \& Bowen, 2001). Additionally, muscle fibril length, leg volume and muscle mass play an important role in muscle strength in anaerobic sport branches (Armstrong, Welsman, \& Chia, 2001). Therefore, an athlete needs a higher amount of muscle mass, muscle cross section, leg volume and mass for a better anaerobic performance (Staron, Hagerman, Hikida, Murray, Hostler, Crill, \& Toma, 2000), which also directly affect muscle strength.

\section{Material and Methods}

This study aims to analyze the relationship among somatotype structures, leg volume, leg mass, anaerobic strength and flexibility of elite male athletes in different branches. 90 male athletes studying at School of Physical Education and Sport at University of Kırşehir Ahi Evran and active performing in wrestling ( $\mathrm{n}=15)$, gymnastics (15), football (15), handball (15), volleyball (15) and basketball $(n=15)$ voluntarily participated in this study. Somatotype structures, leg volumes and leg masses of the participants were determined using Heath-Carter, Frustum and Hanavan methods, respectively. Vertical jump test and sit-and-reach test was used to determine anaerobic performance and flexibility performance, respectively. 


\subsection{Calculation of Leg Volume and Mass}

Femur, calf and feet were measured in order to calculate leg volume. The distance between tibial point and inguinal fold was calculated to find the femur volume. After this distance was measured for each 10 percentile of total length, as defined by frustum sign model method, volumes for each 10 percentile (Formula 1) and volumes of all other parts were summed to calculate total femur volume (Formula 2). In order to find calf volume, the distance between tibial point and medial malleolus point was first calculated. After this distance was measured for each 10 percentile of total length, as defined by frustum sign model method, volumes for each 10 percentile (Formula 1) and volumes of all other parts were summed to calculate total calf volume (Formula 3). Foot volume was measured using medial malleolus (Özkan, \& İşler, 2010; Sukul, Den Hoed, Johannes, Van Dolder, \& Benda 1993).

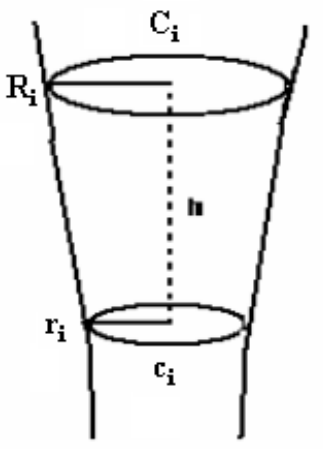

$$
\begin{aligned}
& R_{i}=\frac{c_{i}}{2 \pi}, \quad r_{i}=\frac{c_{i}}{2 \pi} \\
& V_{u}=\sum_{i=1}^{10} \frac{\pi}{3} h\left(R_{i}^{2}+R_{i} r_{i}+r_{i}^{2}\right) \\
& V_{b}=\sum_{i=1}^{10} \frac{\pi}{3} h\left(R_{i}^{2}+R_{i} r_{i}+r_{i}^{2}\right)
\end{aligned}
$$

Figure 1. Calculation of Leg Volume

$$
\begin{aligned}
& \mathrm{Vu}=\text { Femur volume } \\
& \mathrm{Vb}=\text { Calf volume } \\
& \mathrm{Ri}=\text { Radius of wide part of } 10 \text { percentile } \\
& \mathrm{ri}=\text { Radius of narrow part of } 10 \text { percentile } \\
& \mathrm{Ci}=\text { Diameter of wide part of } 10 \text { percentile } \\
& \mathrm{ci}=\text { Diameter of narrow part of } 10 \text { percentile } \\
& \mathrm{h}=\quad \text { Distance between narrow and wide parts of } 10 \text { percentile }
\end{aligned}
$$

\subsubsection{Calculation of Foot Volume}

While the elliptic surface of cross section area ( $\mathrm{Si}$ ) in each part is calculated using Formula 4, volumes of other consecutive parts between the lines were calculated using Frustum model. When calculating foot volume, hi, i+1 is the distance between consecutive foot parts (Formula 5), and $\mathrm{h}$ value, which is L3/2, is the height between line 1 and foot sole, and it varies depending on the foot. $\mathrm{h}$ value between the third and fourth part is $\mathrm{L} 1 / 2$, which varies depending on the foot. The volume of fifth part is calculated using elliptic parabolic Formula 6, while total foot volume is calculated by summing volumes of all parts (Formula 6) (Özkan, \& İşler, 2010; Mayrovitz, Sims, Litwio, \& Pfister, 2005).

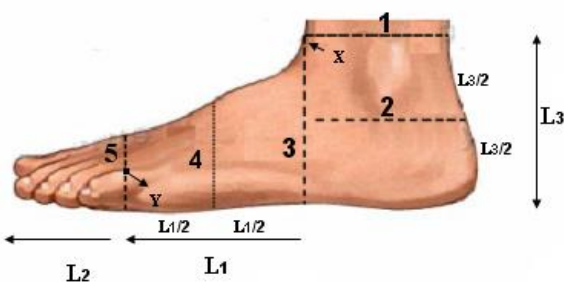

Figure 2. Calculation of Foot Volume

$$
\begin{aligned}
S_{i} & =\prod W_{i} D_{i} / 4 \\
V_{i} & =\left(h_{i, I+1} / 3\right)\left\{S_{i}+S_{i+1}+\left(S_{i} S_{i+1}\right)^{1 / 2}\right\} \\
V_{5} & =\prod L_{2} W_{5} D_{5} / 8 \\
\mathrm{Si} & =\text { Cross section area }
\end{aligned}
$$




$$
\begin{aligned}
\mathrm{Wi} & =\text { Maximum width } \\
\mathrm{Di} & =\text { Maximum depth } \\
\mathrm{Vi} & =\text { Volume } \\
\mathrm{hi} & =\text { Height } \\
\mathrm{V} 5 & =\text { Total foot volume }
\end{aligned}
$$

The foot volume was defined by drawing lines between foot sole and medial malleolus point, volumes of different foot parts were calculated as mentioned above, and, finally, volumes of all parts were summed to calculate total foot volume (Formula 7).

$$
\begin{aligned}
\mathrm{Va} & =\mathrm{V} 1+\mathrm{V} 2+\mathrm{V} 3+\mathrm{V} 4+\mathrm{V} 5 \\
\mathrm{Va} & =\text { Foot volume } \\
\mathrm{V} 1 & =\text { Volume of first part } \\
\mathrm{V} 2 & =\text { Volume of second part } \\
\mathrm{V} 3 & =\text { Volume of third part } \\
\mathrm{V} 4 & =\text { Volume of fourth part } \\
\mathrm{V} 5 & =\text { Volume of fifth part }
\end{aligned}
$$

\subsubsection{Calculation of Leg Mass}

Femur, calf and feet were measured in order to calculate leg mass. The distance between tibial point and inguinal fold was calculated for the femur. The distance between tibial point and medial malleolus point was calculated for the calf. Finally, the foot was first measured using medial malleolus, and later Havanan model method (Özkan \& İşler, 2010; Kwon, 1998). "Leg Volume and Mass Calculation Program” developed by Marangoz and Özbalcı (2017) was used for calculation.

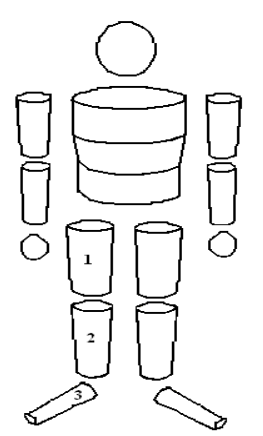

Fig. 3. Hanavan Model Method

$$
\underline{m}=0,074 \mathrm{VA}+0,138 \mathrm{UC}-4,641
$$

$$
\begin{aligned}
\mathrm{m} & =\text { Femur mass } \\
\mathrm{VA} & =\text { Body weight } \\
\mathrm{UÇ} & =\text { The widest femur circumference } \\
\mathrm{m} & =\frac{m=0,135 B C-1,318}{\text { Calf mass }} \\
\mathrm{BÇ} & =\text { The widest calf circumference }
\end{aligned}
$$

$$
\begin{aligned}
& \mathrm{m}=\text { Foot mass } \\
& \mathrm{VA}=\text { Body weight } \\
& \mathrm{ABC}=\quad \text { Ankle circumference } \\
& \mathrm{AU}=\text { Foot length }
\end{aligned}
$$$$
\underline{m=0,003 V A+0,048 A B C+0,027 A U-0,869}
$$

\subsection{Determination of Somatotypes}

The somatotype values of the participants were determined using Heath Carter method. Thanks to factor analysis, this method can easily determine somatotypes among different anthropometric measurements without needing any images. It is based on tables calculated using statistical analyses on some measurements which belong to individuals whose somatotypes are determined using Sheldon Atlas. These tables formulate triceps, subscapula and suprailiac skinfold thickness in order to calculate endomorph points (Formula 11). Humerus epicondyle breadth, femur epicondyle breadth, biceps during flexion, calf circumference, triceps skinfold thickness and medial calf skinfold thickness are measured in order to calculate mesomorph points (Formula 12). Height and weight measurements are used for ectomorph points (Formula 13) (Carter, \& Heath, 1971; Carter, 2002; Carter, \& Heath, 1990; Ross, \& Marfell-Jones, 1991). In addition, 
"SOMATOTURK" program developed by Marangoz \& Özbalcı (2017) was used for calculations.

\subsubsection{Determination of Endomorph}

$A=$ triceps + subscapular + suprailiac

$B=(170.18 /$ height $)$ (Adjustment coefficient for height)

Adjusted sum $X=A . B$

Endomorph $=-0.7182+0.1451(X)-0.00068(X 2)+0.0000014(X 3)$

2.2.2 Determination of Mesomorph

Mesomorph $=(0.858 H B+0.601 F B+0.188 C A G+0.161 C C G)-(0.131 H)+4.5$

HB: Humerus breadth $(\mathrm{cm})$

FB: Femur breadth $(\mathrm{cm})$

CAG: Arm circumference during flexion - Triceps skinfold /10

CCG: Maximal calf circumference - Calf skinfold /10

H: Height (cm)

\subsubsection{Determination of Ectomorph}

Height and weight are calculated in $\mathrm{cm}$ and $\mathrm{kg}$, respectively. Height is divided by the cube root of weight to calculate HWR (HWR=height/cube root of weight). Ectomorph is calculated based on HWR value using one of the formulas below:

IF HWR $\geq 40.75$, Ectomorph $=0.732 \times$ HWR -28.58

IF $38.25<$ HWR $<40.75$, Ectomorph $=0.463 \times$ HWR -17.63

IF HWR $\leq 38.25$, Ectomorph $=0.1$

\subsection{Calculation of Flexibility}

A test table at a dimension of $35 \mathrm{~cm}$ length, $45 \mathrm{~cm}$ width and $32 \mathrm{~cm}$ height was used for Sit-and-Reach-Test in order to measure their muscle flexibility (Raven, Gettman, Pollock, \& Cooper, 1976). Prior to the flexibility measurement, the athletes were given 15 minutes for a warm-up and stretching session. Lower extremity and lumbal extensor flexibility of the athletes were assessed based on sit-and-reach test. The athletes were positioned in a long sitting position with their ankles at a 90 degree angle and their naked soles touching the sit-and-reach table. They were asked to reach forward as far as possible with their hands before their body and without bending their knees and to wait for 2 seconds at this point. The point to which their bodies reached on the ruler on the test table was recorded in centimeters. The measurer stood by the gymnast to prevent them from bending their knees. Finally, the measurement was repeated twice, and the highest value was recorded (Tamer, 2000).

\subsection{Anaerobic Strength Measurement (Vertical Jump Test)}

A digital Takei (Japan) jump meter with a sensitivity of 1 centimeter $(\mathrm{cm})$ was used for performance tests. After the digital indicator of jump meter is fastened around the athlete's waist and its cord is adjusted, the participant jumps upwards by bending his/her knees. After jumping, s/he tries to stand on a rubber mat on the ground which is connected to the jump meter. This process is repeated twice, and the better result is taken into consideration. Lewis formula (Formula 14) is used to calculate for anaerobic strength (Fox, Bowers, \& Foss, 2012).

$$
\begin{aligned}
& P=\sqrt{ } 4.9 \times \text { Body weight } \times \sqrt{ } \mathrm{D} \\
& \mathrm{P}=\text { Anaerobic strength } \\
& \mathrm{D}=\text { Vertical jump distance }(\mathrm{cm})
\end{aligned}
$$

Vertical jump tests are used to measure explosive strength and jumping performance of the athletes. Jumping represents the difference between the height where an athlete can reach and the height where s/he can reach by jumping. In addition, a body's center of gravity should move upwards during jumping. The differences between body weights of participants should be taken into account during the calculation of strength based on jumping results. This is because an athlete with a higher body weight will yield more strength compared to an athlete with a lower body weight (Bizati, 2013).

\subsection{Statistical Analyses}

In this study, descriptive statistics were obtained and Spearman correlation analysis was performed using SPSS 22.0 package program for Windows. The level of significance was taken as 0.05 . 


\section{Findings}

Table 1. Descriptive statistics of the study

\begin{tabular}{|c|c|c|c|c|c|c|}
\hline \multirow[t]{2}{*}{ Variables } & Football $(n=15)$ & Volleyball $(\mathrm{n}=15)$ & Basketball $(n=15)$ & Handball $(n=15)$ & Wrestling $(\mathrm{n}=15)$ & Gymnastics $(\mathrm{n}=15)$ \\
\hline & $x \pm s d$ & $\mathrm{x} \pm \mathrm{sd}$ & $x \pm s d$ & $x \pm s d$ & $\mathrm{x} \pm \mathrm{sd}$ & $\mathrm{x} \pm \mathrm{sd}$ \\
\hline Age (years) & $21.46 \pm .91$ & $22.00 \pm 1.19$ & $22.06 \pm 1.03$ & $21.26 \pm .79$ & $21.40 \pm .82$ & $21.20 \pm .94$ \\
\hline Weight (kg) & $79.00 \pm 5.09$ & $80.46 \pm 5.08$ & $79.80 \pm 5.14$ & $76.60 \pm 6.15$ & $74.40 \pm 7.53$ & $74.33 \pm 6.51$ \\
\hline Height $(\mathrm{cm})$ & $181.33 \pm 6.39$ & $182.46 \pm 3.97$ & $181.80 \pm 6.43$ & $177.73 \pm 5.27$ & $178.06 \pm 5.77$ & $177.00 \pm 4.14$ \\
\hline Right Leg Volume (ml) & $10817.80 \pm 844.59$ & $10819.20 \pm 844.99$ & $11006.80 \pm 926.52$ & $10756.66 \pm 861.08$ & $10759.60 \pm 858.96$ & $10739.20 \pm 877.74$ \\
\hline Left Leg Volume (ml) & $10563.73 \pm 757.10$ & $10567.40 \pm 773.78$ & $10719.06 \pm 919.84$ & $10471.53 \pm 776.69$ & $10480.13 \pm 770.55$ & $10476.40 \pm 773.71$ \\
\hline Right Leg Mass (kg) & $11.93 \pm .72$ & $11.91 \pm .73$ & $11.88 \pm .68$ & $11.87 \pm .66$ & $11.84 \pm .68$ & $11.84 \pm .68$ \\
\hline Left Leg Mass (kg) & $11.76 \pm .83$ & $11.97 \pm .69$ & $11.62 \pm .93$ & $11.42 \pm .97$ & $11.46 \pm 1.00$ & $11.55 \pm .97$ \\
\hline Endomorph Value & $3.86 \pm .51$ & $3.73 \pm .66$ & $3.39 \pm .33$ & $3.41 \pm .85$ & $4.26 \pm .27$ & $2.14 \pm .10$ \\
\hline Mesomorph Value & $4.34 \pm 1.36$ & $3.96 \pm .99$ & $4.31 \pm .29$ & $3.97 \pm .78$ & $5.59 \pm .51$ & $4.06 \pm .60$ \\
\hline Ectomorph Value & $2.60 \pm .63$ & $2.06 \pm .81$ & $2.08 \pm .72$ & $2.13 \pm .75$ & $2.43 \pm .70$ & $3.67 \pm .64$ \\
\hline $\begin{array}{l}\text { Anaerobic } \\
(\mathrm{kg}-\mathrm{m} / \mathrm{sec})\end{array}$ & $\mathrm{h} 107.82 \pm 9.52$ & $111.15 \pm 8.30$ & $107.37 \pm 9.27$ & $107.82 \pm 9.52$ & $108.34 \pm 8,66$ & $108.49 \pm 9.20$ \\
\hline Flexibility (cm) & $28.26 \pm 1.33$ & $29.13 \pm 1.88$ & $27.53 \pm 7.51$ & $27.46 \pm 6.79$ & $30.93 \pm 1.70$ & $37.13 \pm 1.55$ \\
\hline
\end{tabular}

Table 2. Pearson correlation comparisons for somatotype structures, leg volume, leg mass, anaerobic strength and flexibility of elite male athletes in different branches

\begin{tabular}{|c|c|c|c|c|c|c|}
\hline \multicolumn{7}{|c|}{ Football (Endo-Mesomorph) } \\
\hline & & Right Leg Volume & Left Leg Volume & Right Leg Mass & Left Leg Mass & Anaerobic \\
\hline Left Leg Volume & $\mathrm{r}$ & $.975^{* * *}$ & & & & \\
\hline Right Leg Mass & $\mathrm{r}$ & $.890^{* * * *}$ & $.834^{* * *}$ & & & \\
\hline Left Leg Mass & $\mathrm{r}$ & $.692^{* *}$ & $.666^{* *}$ & $.622^{*}$ & & \\
\hline Anaerobic & $\mathrm{r}$ & $.801^{* * * *}$ & $.807^{* * *}$ & $.602^{*}$ & $.841^{* * *}$ & \\
\hline Flexibility & $\mathrm{r}$ & -.068 & -.149 & .070 & -.085 & -.092 \\
\hline \multicolumn{7}{|c|}{ Volleyball (Endomorph - Mesomorph) } \\
\hline & & Right Leg Volume & Left Leg Volume & Right Leg Mass & Left Leg Mass & Anaerobic \\
\hline Left Leg Volume (ml) & $\mathrm{r}$ & $.969^{* * *}$ & & & & \\
\hline Right Leg Mass (kg) & $\mathrm{r}$ & $.849^{* * * *}$ & $.847^{* * *}$ & & & \\
\hline Left Leg Mass (kg) & $\mathrm{r}$ & $.708^{* *}$ & $.637^{*}$ & $.711^{* *}$ & & \\
\hline Anaerobic & $\mathrm{r}$ & $.604^{*}$ & $.602^{*}$ & .371 & $.758^{* *}$ & \\
\hline Flexibility & $\mathrm{r}$ & .176 & .160 & .111 & .276 & .275 \\
\hline \multicolumn{7}{|c|}{ Basketball (Endo-Mesomorph) } \\
\hline & & Right Leg Volume & Left Leg Volume & Right Leg Mass & Left Leg Mass & Anaerobic \\
\hline Left Leg Volume (ml) & $\mathrm{r}$ & $.953^{* * *}$ & & & & \\
\hline Right Leg Mass (kg) & $\mathrm{r}$ & $.894^{* * * *}$ & $.839^{* *}$ & & & \\
\hline Left Leg Mass (kg) & $\mathrm{r}$ & .470 & .479 & $.618^{*}$ & & \\
\hline Anaerobic & $\mathrm{r}$ & $.731^{* *}$ & $.679^{* *}$ & $.640^{*}$ & $.724^{* *}$ & \\
\hline Flexibility & $\mathrm{r}$ & -.067 & -.052 & .018 & -039 & -.212 \\
\hline \multicolumn{7}{|c|}{ Handball (Endo-Mesomorph) } \\
\hline & & Right Leg Volume & Left Leg Volume & Right Leg Mass & Left Leg Mass & Anaerobic \\
\hline
\end{tabular}




\begin{tabular}{|c|c|c|c|c|c|c|}
\hline Right Leg Mass (kg) & $\mathrm{r}$ & $.857^{* * * *}$ & $.812^{* * * *}$ & & & \\
\hline Left Leg Mass (kg) & $\mathrm{r}$ & $.758^{* *}$ & $.753^{* *}$ & $.729^{* *}$ & & \\
\hline Anaerobic & $\mathrm{r}$ & $.795^{* * *}$ & $.805^{* * *}$ & $.683^{* *}$ & $.637^{*}$ & \\
\hline Flexibility & $\mathrm{r}$ & .419 & .273 & $.552^{*}$ & .384 & .425 \\
\hline \multicolumn{7}{|c|}{ Wrestling (Endo-Mesomorph) } \\
\hline & & Right Leg Volume & Left Leg Volume & Right Leg Mass & Left Leg Mass & Anaerobic \\
\hline Left Leg Volume (ml) & $\mathrm{r}$ & $.981^{* * *}$ & & & & \\
\hline Right Leg Mass (kg) & $\mathrm{r}$ & $.872^{* * *}$ & $.828^{* * *}$ & & & \\
\hline Left Leg Mass (kg) & $\mathrm{r}$ & $.709^{* *}$ & $.714^{* *}$ & $.621^{*}$ & & \\
\hline Anaerobic & $\mathrm{r}$ & $.825^{* * * *}$ & $.851^{* * * *}$ & $.681^{* *}$ & $.608^{*}$ & \\
\hline Flexibility & $\mathrm{r}$ & $.529^{*}$ & $.535^{*}$ & .341 & .263 & .415 \\
\hline
\end{tabular}

Gymnastics (Mesomorph - Ectomorph)

\begin{tabular}{|c|c|c|c|c|c|c|}
\hline \multicolumn{2}{|c|}{ Mesomorph - Ectomorph } & Right Leg Volume & Left Leg Volume & Right Leg Mass & Left Leg Mass & Anaerobic \\
\hline Left Leg Volume (ml) & $\mathrm{r}$ & $.980^{* * * *}$ & & & & \\
\hline Right Leg Mass (kg) & $\mathrm{r}$ & $.873^{* * *}$ & $.829^{* * *}$ & & & \\
\hline Left Leg Mass (kg) & $\mathrm{r}$ & $.625^{*}$ & $.653^{* *}$ & $.635^{*}$ & & \\
\hline Anaerobic & $\mathrm{r}$ & $.751^{* *}$ & $.787^{* *}$ & $.590^{*}$ & $.726^{* *}$ & \\
\hline Flexibility & $\mathrm{r}$ & .463 & .498 & .458 & .353 & .421 \\
\hline
\end{tabular}

p $<0.05^{* *} \mathrm{p}<0.01^{* * *} \mathrm{p}<0.01$

\section{Discussion}

This study indicates:

For football players, a very highly positive significant correlation $(\mathrm{r}=.801, \mathrm{p}<0.001)$ between right leg volume and anaerobic strength, a very highly positive significant correlation $(r=.807, p<0.001)$ between left leg volume and anaerobic strength, a highly positive significant correlation $(r=.602, p<0.05)$ between right leg mass and anaerobic strength, and a very highly positive significant correlation $(r=.841, p<0.001)$ between left leg mass and anaerobic strength. No significant correlation $(\mathrm{p}>0.05)$ was found between leg volume and mass and flexibility.

For volleyball players, a highly positive significant correlation $(r=.605, \mathrm{p}<0.05)$ between right leg volume and anaerobic strength, a highly positive significant correlation $(\mathrm{r}=.602, \mathrm{p}<0.05)$ between left leg volume and anaerobic strength, and a highly positive significant correlation $(r=.758, p<0.01)$ between left leg mass and anaerobic strength. No significant correlation ( $\mathrm{p}>0.05$ ) was found between leg volume and mass and flexibility.

For basketball players, a highly positive significant correlation $(\mathrm{r}=.731, \mathrm{p}<0.01)$ between right leg volume and anaerobic strength, a highly positive significant correlation $(\mathrm{r}=.679, \mathrm{p}<0.01)$ between left leg volume and anaerobic strength, a highly positive significant correlation $(\mathrm{r}=.640, \mathrm{p}<0.05)$ between right leg mass and anaerobic strength, and a highly positive significant correlation $(r=.724, \mathrm{p}<0.01)$ between left leg mass and anaerobic strength. No significant correlation ( $\mathrm{p}>0.05)$ was found between leg volume and mass and flexibility.

For handball players, a highly positive significant correlation $(r=.795, \mathrm{p}<0.001)$ between right leg volume and anaerobic strength, a very highly positive significant correlation $(r=.805, \mathrm{p}<0.001)$ between left leg volume and anaerobic strength, a highly positive significant correlation $(r=.683, p<0.01)$ between right leg mass and anaerobic strength, and a highly positive significant correlation $(r=.637, \mathrm{p}<0.05)$ between left leg mass and anaerobic strength. No significant correlation ( $\mathrm{p}>0.05$ ) was found between leg volume and mass and flexibility.

For wrestlers, a very highly positive significant correlation $(\mathrm{r}=.825, \mathrm{p}<0.001)$ between right leg volume and anaerobic strength, a very highly positive significant correlation $(\mathrm{r}=.851, \mathrm{p}<0.001)$ between left leg volume and anaerobic strength, a highly positive significant correlation $(\mathrm{r}=.681, \mathrm{p}<0.01)$ between right leg mass and anaerobic strength, a highly positive significant correlation $(\mathrm{r}=.608, \mathrm{p}<0.05)$ between left leg mass and anaerobic strength, a moderate positive significant correlation $(\mathrm{r}=.529, \mathrm{p}<0.05)$ between right leg volume and flexibility, and a moderate positive significant correlation $(\mathrm{r}=.535, \mathrm{p}<0.05)$ between left leg volume and flexibility. 
For gymnasts, a very highly positive significant correlation $(\mathrm{r}=.751, \mathrm{p}<0.01)$ between right leg volume and anaerobic strength, a very highly positive significant correlation $(r=.787, p<0.001)$ between left leg volume and anaerobic strength, a very highly positive significant correlation $(\mathrm{r}=.590, \mathrm{p}<0.05)$ between right leg mass and anaerobic strength, and a very highly positive significant correlation $(\mathrm{r}=.726, \mathrm{p}<0.01)$ between left leg mass and anaerobic strength. No significant correlation ( $p>0.05$ ) was found between leg volume and mass and flexibility.

De Ste Croix, Armstrong, Chia, Welsman, Parsons \& Sharpe (2000) reported that leg volume increased in proportion to ageing, thus leading to a significant effect on the anaerobic performance. Özkan \& Sarol (2008) found a significant correlation between leg volume and mass and anaerobic performance values. It was demonstrated in various studies that athletes with a higher amount of muscle fiber, muscle mass, muscle cross section, leg volume and leg mass displayed a better anaerobic performance (Staron, Hagerman, Hikida, Murray, Hostler, Crill, \& Toma, 2000). Additionally, as indicated by some studies, a correlation was found between anaerobic power and femur breadth, femur length and height. Therefore, it can be argued that athletes with a higher femur length and wider femur breadth may have a higher anaerobic strength. Finally, the difference between values of right and left legs may result from dominant legs in different branches.

In conclusion, a significant correlation was found between anaerobic strength and leg volume and leg mass in football, volleyball, basketball, handball, wrestling and gymnastics. This relationship plays a decisive role in anaerobic performance. It can be observed that athletes with a higher leg volume and mass display a higher anaerobic performance. A higher femur breadth and a higher amount of muscle mass and fiber are more likely to result in a higher muscle strength, which influences maximum strength. In addition, it must be noted that speed, strength, agility and flexibility are important training and performance parameters in various sport branches. In addition to these parameters, it can be suggested that leg volume and mass be considered as a parameter because they contribute to the performance in a given sport branch.

\section{References}

Armstrong, N., Welsman, J. R., \& Chia, M. Y. H. (2001). Short term power output in relation to growth and maturation. British Journal of Sports Medicine, 35, 118-124. https://doi.org/10.1136/bjsm.35.2.118

Bencke, J., Damsgaard, R., Saekmose, A., Jorgenson, P., Jorgenson, K., \& Klauen, K. (2002). Anaerobic power and muscle strength characteristics of 11 years old elite and non-elite boys and girls from gymnastics, team handball, tennis and swimming. Scandinavian Journal of Medicine and Science in Sports, 12, 171-178. https://doi.org/10.1034/j.1600-0838.2002.01128.x

Bizati, Ö. (2013). Comparision of Different Evaluation Methods of Professional Soccer Players' Physical and Physiological Characteristics. Ankara University, Department of Physical Education and Sports, Doctorate Thesis, Ankara.

Carter, J. E. L. (2002). The Heath-Carter Anthropometric Somatotype-Instruction Manual. San Diego, USA.

Carter, J. E. L., \& Heath, B. H. (1971). Somatotype Methodology and Kinesiology Reseach. Kinesiology Review, 1971, 10-19.

Carter, J. E. L., \& Heath, B. H. (1990). Somatotyping - Development and Applications. New York: Cambridge University Press.

De Ste Croix, M. B. A., Armstrong, N., Chia, M. Y. H., Welsman, J. R., Parsons, G., \& Sharpe, P. (2000). Changes in short term power output in 10 to 12-year-olds. Journal of Sports of Sciences, 19, 141-148. https://doi.org/10.1080/026404101300036352

Dore, E., Bedu, M., França, N. M., \& Praagh, E. V. (2001). Anaerobic cycling performance characteristics in prepubescent, adolescent and young adults females, European Journal of Applied Physiology., 84, 476-481. https://doi.org/10.1007/s004210100385

Fox, E. L., Bowers, R. W., \& Foss, M. L. (2012). Physiological Foundations of Physical Education and Sports Eds. Mesut Cerit). Ankara.

Kwon, Y. H. (1998). Modified Hanavan Model. (http://www.kwon3d.com/theory/bspeq/hanavan.html/.) (08.9.2016).

Marangoz, İ., \& Özbalcı, Ü. (2017). Leg volume and mass calculation program in sports, The Journal of Academic Social Science, 48(5), 223-231.

Marangoz, I., \& Özbalc1, Ü. (2017). Somatotype calculation program (SOMATOTURK), The Journal of Academic Social Science, 47(5), 288-293. 
Marangoz, İ., \& Polat, Y. (2017). The effects of body composition and somatotypes on acceleration speed in male athletes, The Journal of Academic Social Science, 54(5), 345-360.

Mayhew, J. L., Hancook, K., Rollisan, L., Ball, T. E., \& Bowen, J. C. (2001). Contributions of strength and body composition to the gender difference in anaerobic power. Journal of Sports Medicine and Physical Fitness, 41, 33-38.

Mayrovitz, H. N., Sims, N., Litwio, B., \& Pfister, S. (2005). Foot Volume Estimates Based on a Georietric Algorithm in Comparison to Water Displacement. Lymphology, 38, 20-22.

Özkan, A, \& Kin, İ. A. (2010). Relationship of leg volume, leg mass, anaerobic performance and isokinetic strength in American football players. Spormetre, 8(1), 35-41.

Özkan, A., \& Sarol, H. (2008). Relationship between body composition, leg volume, leg mass, anaerobic performance and knee strength in climbers. Spormetre, VI(4), 175-181.

Raven, P. B., Gettman, L. R., Pollock, M. L., \& Cooper, K. H. (1976). A physiological evaluation of professional soccer players. British Journal of Sports Medicine, 10(4), 209-216. https://doi.org/10.1136/bjsm.10.4.209

Ross, W. D., \& Marfell-Jones, M. J. (1991). Kinanthropometry. In MacDougall, DJ., Wenger AH \& Green H J. (Eds). Physiological Testing of the High-Performance Athlete. Illinois: Human Kinetics Books, 223-308.

Staron, R. S., Hagerman, F. C., Hikida, R. S., Murray, T. F., Hostler, D. P., \& Crill, M. T. T. (2000). Fiber type composition of the vastus lateralis muscle of young men and women. The Journal of Histochemistry and Cytochemistry, 48(5), 623-629. https://doi.org/10.1177/002215540004800506

Sukul, D. K., Den Hoed, P. T., Johannes, E. J., Van Dolder, R., \& Benda, E. (1993). Direct and indirect methods for the quantification of leg volume: comparison between water displacement volumetry, the disk model method and the frustum sign model method, using the correlation coefficient and the limits of agreement. Journal of Biomedical Engineering, 15(6), 477-480. https://doi.org/10.1016/0141-5425(93)90062-4

Tamer, K. (2000). Sporda Fiziksel Fizyolojik Performansın Ölçülmesi ve Değerlendirilmesi. Ankara.

\section{Copyrights}

Copyright for this article is retained by the author(s), with first publication rights granted to the journal.

This is an open-access article distributed under the terms and conditions of the Creative Commons Attribution license which permits unrestricted use, distribution, and reproduction in any medium, provided the original work is properly cited. 